\title{
Accumulation of prion protein in muscle fibers of experimental chloroquine myopathy: in vivo model for deposition of prion protein in non-neuronal tissues
}

\author{
Hisako Furukawa*, Katsumi Doh-ura ${ }^{\dagger}$, Kensuke Sasaki and Toru Iwaki \\ Department of Neuropathology, Neurological Institute, Graduate School of Medical Sciences, Kyushu \\ University, Fukuoka, Japan
}

\begin{abstract}
Prion protein ( $\operatorname{PrP})$ is known to accumulate in some non-neuronal tissues under conditions unrelated to prion diseases. The biochemical and biological nature of such accumulated PrP molecules, however, has not been fully evaluated. In this study, we established experimental myopathy in hamsters by long-term administration of chloroquine, and we examined the nature of the PrP molecules that accumulated. PrP accumulation was immunohistochemically demonstrated in autophagic vacuoles in degenerated muscle fibers, and this was accompanied by the accumulation of other molecules related to the neuropathogenesis of prion diseases such as clathrin, cathepsin B, heparan sulfate, and apolipoprotein J. Accumulated PrP molecules were partially insoluble in detergent solution and were slightly less sensitive to proteinase $\mathrm{K}$ digestion than normal cellular PrP. Muscle homogenates containing these PrP molecules did not cause disease in inoculated hamsters. The findings indicate that the PrP molecules that accumulated in muscle fibers have distinct biochemical and biological properties. Therefore, experimental chloroquine myopathy is a novel and useful model to investigate the mechanism of deposition of PrP in non-neuronal tissues and might provide new insights in the pathogenesis of prion diseases.

Laboratory Investigation (2004) 84, 828-835, advance online publication, 3 May 2004; doi:10.1038/labinvest.3700111
\end{abstract}

Keywords: detergent-solubility; experimental chloroquine myopathy; lysosome; non-neuronal tissues; prion protein; protease sensitivity

Prion diseases such as Creutzfeldt-Jakob disease in humans, and scrapie and bovine spongiform encephalopathy in animals are neurodegenerative disorders characterized by the accumulation in the brain of a protease-resistant, detergent-insoluble abnormal isoform of prion protein (PrP). This abnormal isoform of $\operatorname{PrP}\left(\mathrm{PrP}^{\mathrm{Sc}}\right)$ is pathogenic itself and replicates by altering the conformation of a protease-sensitive, detergent-soluble normal cellular isoform of prion protein $\left(\mathrm{PrP}^{\mathrm{C}}\right) .{ }^{1}$ In addition to the

Correspondence: Dr H Furukawa, MD, PhD, Department of Pharmacology 1, Nagasaki University Graduate School of Biomedical Sciences, 1-12-4 Sakamoto, Nagasaki 852-8523, Japan.

E-mail: hisako@net.nagasaki-u.ac.jp

${ }^{*}$ Current address: Department of Pharmacology 1, Nagasaki University Graduate School of Biomedical Sciences, 1-12-4 Sakamoto, Nagasaki 852-8523, Japan.

'Division of Prion Protein Biology, Department of Prion Research, Tohoku University Graduate School of Medicine, 2-1 Seiryo-cho, Aoba-ku, Sendai 980-8575, Japan.

Received 16 January 2004; revised 7 March 2004; accepted 12 March 2004; published online 3 May 2004 central nervous system, $\operatorname{PrP}^{\mathrm{Sc}}$ deposition is observed in non-neuronal tissue such as tonsils and skeletal muscles in human prion diseases ${ }^{2,3}$ and experimental animals. ${ }^{4}$

PrP is also known to accumulate in non-neuronal tissues under certain pathological conditions unrelated to prion diseases. Frederiske et $a l^{5}$ recently revealed increased $\mathrm{PrP}$ immunoreactivity in the regions of fiber-cell degeneration in cataractous lenses in humans. Askanas et $a l^{6}$ reported the accumulation of PrP in vacuolated muscle fibers, in angulated and round atrophic fibers with sarcolemmal enhancement, and in the perivascular inflammatory cells of sporadic inclusion-body myositis in humans. ${ }^{6,7}$ It was also reported that the accumulated $\mathrm{PrP}$ molecules were sensitive to protease treatment. ${ }^{7}$ However, the biochemical and biological characteristics of these PrP molecules have not been fully evaluated.

Chloroquine, a widely used antimalarial agent, is known to be concentrated in lysosomes and to cause elevation of intralysosomal $\mathrm{pH} .{ }^{8}$ Long-term 
administration of chloroquine sometimes causes myopathy, termed chloroquine myopathy (CM), which is characterized by degenerated muscle fibers with numerous autophagic, rimmed vacuoles. ${ }^{9}$ Tsuzuki et $a l^{10}$ established experimental CM in the rat to investigate the mechanism of accumulation of the proteins related to Alzheimer's disease in rimmed vacuoles, because of its histopathological similarity to human myopathies where amyloid $\beta$ deposition is observed in rimmed vacuoles.

To explore the biochemical and biological properties of PrP molecules that accumulate under pathological conditions unrelated to prion diseases, we established experimental CM in hamsters and characterized the PrP molecules ( $\mathrm{PrP} \mathrm{PQ}^{\mathrm{CO}}$ ) that accumulated in affected muscle fibers.

\section{Materials and methods}

\section{Animals and Reagents}

Female Syrian hamsters, 3-8-week old, were purchased from SLC (Hamamatsu, Japan). Chloroquine diphosphate and Nonidet P-40 (NP-40) were purchased from Sigma Chemical (MO, USA). Proteinase $\mathrm{K}(\mathrm{PK})$ and complete mini protease inhibitor cocktail were obtained from Roche Molecular Biochemicals (Germany). Monoclonal antibody 3F4 recognizing hamster PrP109-112 was from Senetek (St Louis, MO, USA). Anti-prion protein polyclonal antibody PrP2B was raised by immunization of rabbits with a hamster PrP89-103 fragment. Polyclonal antibodies for apolipoprotein J (clusterin) and for cathepsin B, and monoclonal antibodies CHC5.9 for clathrin and HepSS-1 for heparan sulfate were purchased from Chemicon (Temecula, CA, USA), Calbiochem (Cambridge, MA, USA), PROGEN Biotechnik GmbH (Germany), and Seikagaku Corporation (Japan), respectively.

\section{Experimental CM in Hamsters}

Hamsters received $50 \mathrm{mg} / \mathrm{kg}$ chloroquine diphosphate $(10 \mathrm{mg} / \mathrm{ml}$ in sterile saline, $\mathrm{pH} 7.6)$ as daily intraperitoneal injections for 60 days. Then the hamsters were killed by decapitation under deep anesthesia. Bilateral soleus, tibialis anterior, and quadriceps muscles were removed and immediately snap-frozen in isopentane cooled with liquid nitrogen. Frozen muscles were kept at $-80^{\circ} \mathrm{C}$ until analysis.

\section{Immunohistochemical Studies}

After the blockage of endogenous peroxidase with $0.3 \%$ hydrogen peroxide in methanol, serial $10-\mu \mathrm{m}$ thick sections of frozen muscle were incubated overnight at $4{ }^{\circ} \mathrm{C}$ with the primary antibodies diluted with $10 \mathrm{mM}$ phosphate-buffered saline (PBS) containing $1 \%$ normal hamster serum. The sections were then incubated with horseradish peroxidaseconjugated secondary antibodies for $1 \mathrm{~h}$ followed by reactions with 3,3'-diaminobenzidine $/ \mathrm{H}_{2} \mathrm{O}_{2}$ and counterstained with hematoxylin. The serial sections were stained with hematoxylin and eosin (HE), or stained for acid phosphatase or by a modified Gomori-trichrome method.

Brain specimens obtained in some experiments were immersion-fixed in $10 \%$ buffered formalin for $24 \mathrm{~h}$ at $4^{\circ} \mathrm{C}$ and embedded in paraffin for immunohistochemical examination. For detection of abnormal PrP deposition, deparaffinized $8-\mu \mathrm{m}$ thick sections were treated with hydrolytic autoclaving prior to incubation with $3 \mathrm{~F} 4$ monoclonal antibody. ${ }^{11}$

\section{Protease Sensitivity Assay of PrPCQ}

After confirmation of the histological findings, the remaining frozen muscle was homogenized using Tissue-Tearor (Biospec Products, Oklahoma) in 10 volumes of lysis buffer A (0.5\% NP-40, $0.5 \%$ sodium deoxycholate in PBS pH 7.4). Homogenates were centrifuged at $3300 \times g$ for $15 \mathrm{~min}$ to remove the nuclear fraction and debris. The supernatant was then treated with the indicated amount of PK at $37^{\circ} \mathrm{C}$ for $20 \mathrm{~min}$. After stopping the digestion with $4 \mathrm{mM}$ 4-[2-aminoethyl]-benzenesulfonyl fluoride (Pefabloc, Roche, Germany), an aliquot corresponding to $4 \mathrm{mg}$ of muscle tissue was analyzed by Western blotting using polyclonal antibody PrP2B. Labeled PrP was visualized by using CDP-star detection reagent (Amersham, UK).

\section{Detergent Solubility Assay of $\operatorname{PrP}^{\mathrm{CQ}}$}

The detergent solubility of $\mathrm{PrP}^{\mathrm{CQ}}$ was determined as described by Lehmann and Harris ${ }^{12}$ with minor modification. Briefly, soleus muscle samples from either control or CM hamsters were homogenized in lysis buffer B (15 mM NaCl, $50 \mathrm{mM}$ Tris-HCl pH 7.5, complete-mini protease inhibitor cocktail) containing the designated concentration of NP-40. Homogenate was centrifuged for $5 \mathrm{~min}$ at $1600 \mathrm{~g}$ to remove debris and the nuclear fraction. The supernatant was ultracentrifuged at $265000 \mathrm{~g}$ for $40 \mathrm{~min}$ at $25^{\circ} \mathrm{C}$. Proteins in the supernatant and in the pellet were separately recovered and analyzed by Western blotting using monoclonal antibody $3 \mathrm{~F} 4$.

\section{Intracerebral Inoculation of PrPCQ}

Inoculum was prepared by homogenizing muscular tissue from CM hamsters or the control in 10 volumes of sterile saline, and $20 \mu \mathrm{l}$ of the inoculum was injected into the brain of 193 -week-old female hamsters under deep anesthesia. The hamsters were observed for over 2 years and killed to examine PrP molecules in the brain immunohistochemically. 


\section{Densitometry and Statistical Analysis}

Blots of the gels were scanned with a CanoScan D2400UF (Canon, Japan). Densities of bands were quantified using NIH Image software. Statistical significance of densitometric data was analyzed by repeated measure ANOVA, and statistical comparison at each dose point between groups was made by Student's $t$-test or Welch's $t$-test.

\section{Ethics}

Animal handling and killing were in accordance with the nationally prescribed guidelines, with ethical approval for the study granted by the Animal Experiment Committee of Kyushu University.

\section{Results}

\section{Histochemical Findings of CM}

All the muscle specimens taken from chloroquinetreated hamsters showed various degrees of myopathic changes accompanied with rimmed vacuoles (Figure 1a), and this was consistent with histopathological findings of experimental $\mathrm{CM}$ in the rat. $^{9,10}$ In addition to the rimmed vacuoles, many muscle fibers contained coarse granular structures that were strongly stained by hematoxylin (Figure 1c) and modified Gomori trichrome stain (Figure $1 \mathrm{~g}$ ), and they showed enhanced acid phosphatase activity (Figure 1h). These abnormal structures were observed in about $10 \%$ of muscle fibers in the soleus muscle which was the most affected in all the muscles of chloroquine-treated hamsters. In contrast, muscles of control hamsters did not contain any rimmed vacuoles or coarse granular structures.

All of the rimmed vacuoles and the coarsely granular structures in degenerated muscle fibers of CM were positively stained by an anti-PrP monoclonal antibody, 3F4, recognizing hamster PrP109112 (Figure 1b, d). In control hamster muscles, the 3F4 monoclonal antibody reacted with sarcolemmal membranes (data not shown).

To investigate the possible involvement of some molecules that relate to the metabolism of $\mathrm{PrP}^{\mathrm{C}}$ or the deposition of $\mathrm{PrP}^{\mathrm{Sc}}$, serial sections were immunostained for apolipoprotein J (Figure 1e), clathrin (Figure 1f), cathepsin B (Figure 1i), and heparan sulfate (Figure 1j). Immunoreactivities for

Figure 1 Immunohistochemical findings in CM muscles. Transverse sections of chloroquine-treated $(50 \mathrm{mg} / \mathrm{kg} / \mathrm{day}$ for 60 days) hamster soleus muscles are shown. (a) HE stain shows rimmed vacuole formation (arrow heads). (b) Immunoreactivity for PrP is detected in a rimmed vacuole (arrow heads) shown in (a). (c-f), (g-j) Serial sections stained with HE (c), modified Gomori trichrome (g), acid phosphatase (h), and immunostained for PrP (d), apolipoprotein J (e), clathrin (f), cathepsin B (i), and heparan sulfate (j). Scale bars $=20 \mu \mathrm{m}$. these molecules were enhanced in the rimmed vacuoles and coarse granular structures in the affected muscle fibers of CM.
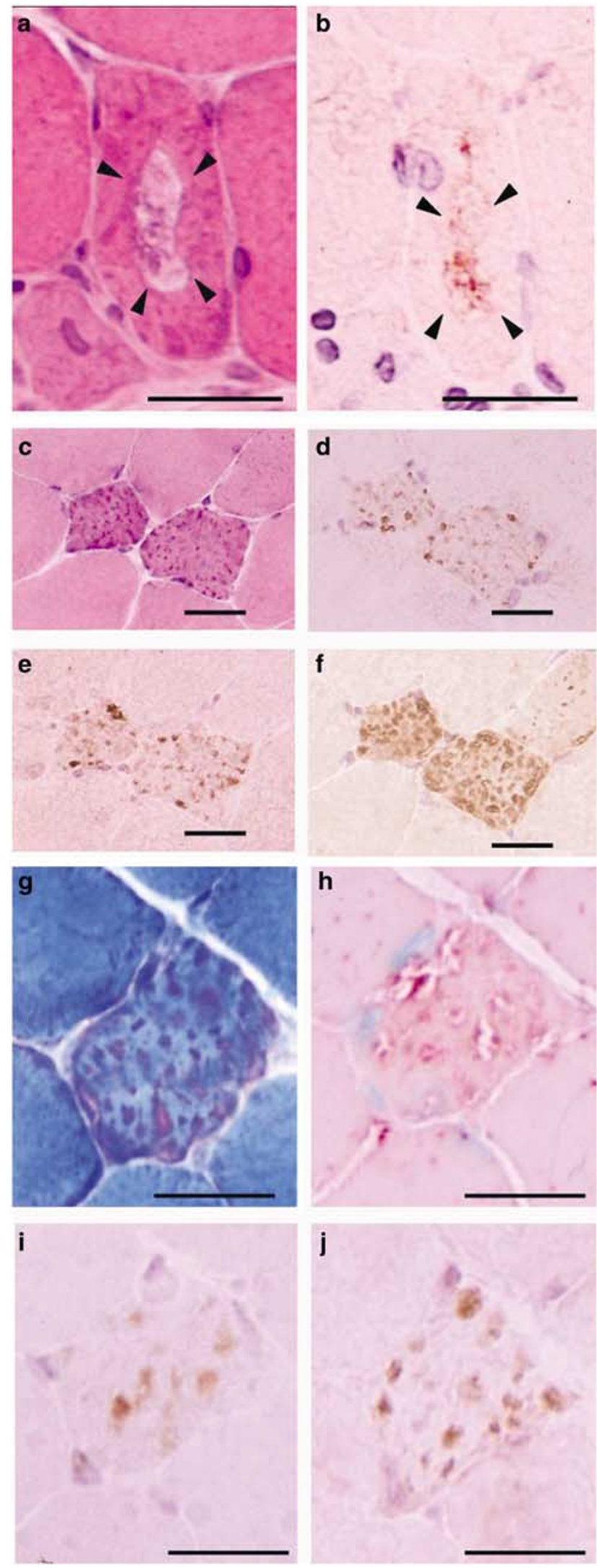


\section{$\operatorname{PrP}^{\mathrm{CQ}}$ is Slightly Less Sensitive to PK Digestion}

Western blot analysis using a polyclonal antibody PrP2B, raised against hamster PrP89-103, revealed prominent bands of 27 and $30 \mathrm{kDa}$ in either CM muscular homogenates or the control, before digestion with PK. There was no significant difference in the intensity of PrP signals between CM muscles and controls (first lanes, Figure 2a, b). The specificity of these bands was confirmed by absorbing the PrP2B antibody with synthetic peptide PrP89-103 (Figure 2c). Although both of the PrP molecules were completely digested with $50 \mu \mathrm{g} / \mathrm{ml}$ of PK, which was the stringent condition to distinguish $\mathrm{PrP}^{\mathrm{Sc}}$ from $\mathrm{PrP}^{\mathrm{C}}$ (data not shown), digestion with a smaller amount of PK revealed different PK sensitivity between the PrP molecules from CM muscles ( $\mathrm{PrP}^{\mathrm{CQ}}$ ) and $\mathrm{PrP}^{\mathrm{C}}$ from the control muscles. $\operatorname{PrP}^{\mathrm{C}}$ derived from control hamster muscle was appar- ently digested with $0.375 \mu \mathrm{g} / \mathrm{ml}$ of $\mathrm{PK}$, whereas a considerable amount of $\operatorname{PrP}^{\mathrm{CQ}}$ of $27 \mathrm{kDa}$ still remained after treatment with $1.0 \mu \mathrm{g} / \mathrm{ml}$ of PK (Figure 2a and b). Statistical analysis of the relative density of the bands revealed a significant difference between $\mathrm{PrP}^{\mathrm{C}}$ and $\mathrm{PrP}^{\mathrm{CQ}}$ after treatment with 0.5, 0.75 , or $1.0 \mu \mathrm{g} / \mathrm{ml}$ of PK (Figure $2 \mathrm{~d}$ ).

\section{$\operatorname{PrP}^{\mathrm{CQ}}$ is Partially Insoluble in Detergent}

Western blot analysis using a monoclonal antibody $3 \mathrm{~F} 4$ revealed prominent signals at $35 \mathrm{kDa}$ and additional signals at about $30 \mathrm{kDa}$ in the supernatants from either CM muscle homogenate or the control (first lanes, Figure $3 \mathrm{a}, \mathrm{b}$ ). While $\mathrm{PrP}^{\mathrm{C}}$ from control muscle was completely solubilized in the lysis buffer containing $0.5 \%$ NP-40 (Figure 3a), a considerable amount of $\mathrm{PrP}^{\mathrm{CQ}}$ remained in the

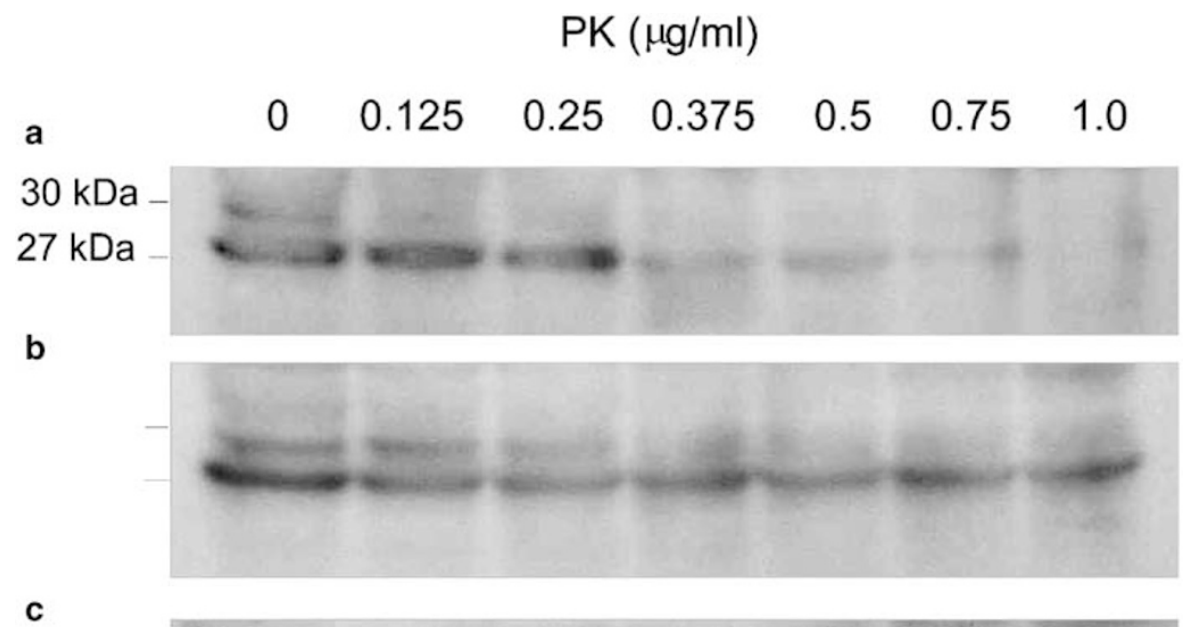

C

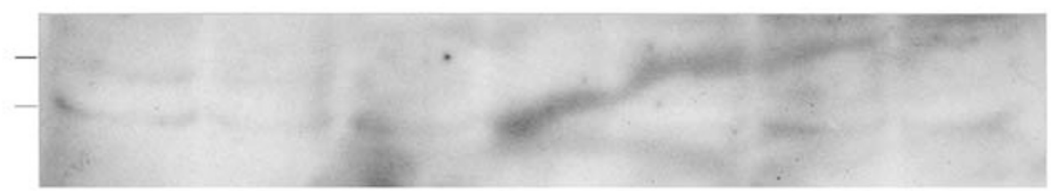

d

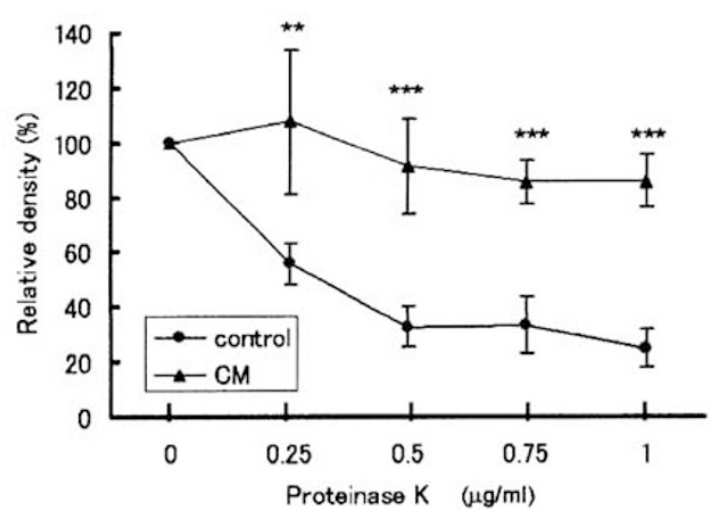

Figure 2 PK sensitivity of PrP molecules in CM muscles. (a-c) PrP molecules in the homogenate of control hamsters (a) or CM hamsters (b) were detected with PrP2B antibody after digestion with a designated amounts of PK at $37^{\circ} \mathrm{C}$ for 20 min. Prominent bands of $27 \mathrm{kDa}$ and $30 \mathrm{kDa}$ were diminished after the antibody had been absorbed by a synthetic polypeptide used for immunization (c). (d) Densitometric analysis of 27 and $30 \mathrm{kDa}$ bands. Data from three independent experiments are indicated. ${ }^{* *} P<0.05,{ }^{* *} P<0.01$. 


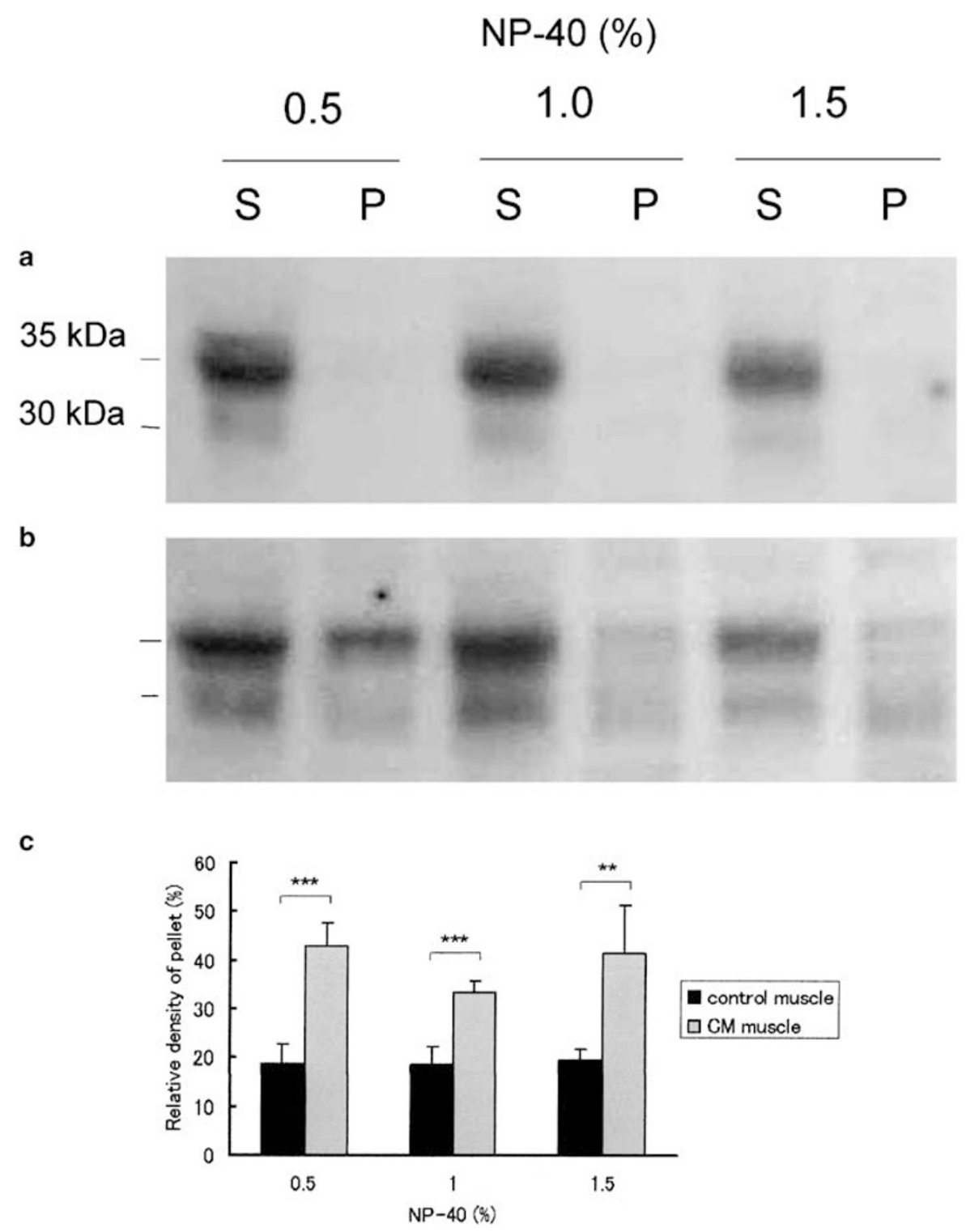

Figure 3 Solubility in NP-40 of PrP molecules in CM muscles. (a, b) Muscles from control hamsters (a) or CM hamsters (b) were homogenized in the lysis buffer containing designated amount of NP-40 and subsequently ultracentrifuged at $265000 \mathrm{~g}$ to separate detergent-soluble PrP molecules in the supernatant $(\mathrm{S})$ and detergent-insoluble molecules in the pellet (P). PrP molecules were labeled with 3F4 monoclonal antibody. (c) Relative PrP amount in the pellet fraction. Percentage of PrP signals ( 30 and $35 \mathrm{kDa})$ of the pellet fraction in the sum of those of the pellet and the supernatant is shown. Data from three independent experiments. ${ }^{* *} P<0.05,{ }^{* *} P<0.01$.

insoluble fraction in the presence of $0.5,1.0$, or $1.5 \%$ NP-40 (Figure 3b, c).

\section{$\operatorname{PrP}^{\mathrm{CQ}}$ is not Pathogenic}

To investigate whether $\mathrm{PrP}^{\mathrm{CQ}}$ is able to cause pathological changes characteristic of prion diseases in vivo, $10 \%$ muscular homogenates containing $\mathrm{PrP}^{\mathrm{CQ}}$ were injected into the brain of Syrian hamsters. The hamsters were observed over 2 years after the inoculation had been given, and none of them developed any signs of prion diseases nor muscle disorders (data not shown). Histological examination of the brain revealed no significant pathological findings or abnormal PrP deposition (Figure 4).

\section{Discussion}

In this study, we have demonstrated that slightly less PK-sensitive and partially detergent-insoluble $\operatorname{PrP}^{\mathrm{CQ}}$ accumulated in affected muscle fibers of experimental CM in hamsters. While PrP molecules from control muscle were sensitive to PK digestion at $0.375 \mu \mathrm{g} / \mathrm{ml}$ and fully soluble in buffer containing $0.5 \%$ NP-40, $\mathrm{PrP}^{\mathrm{CQ}}$ molecules were less sensitive to PK digestion up to $1.0 \mu \mathrm{g} / \mathrm{ml}$, and a considerable portion of them was insoluble in buffer containing 

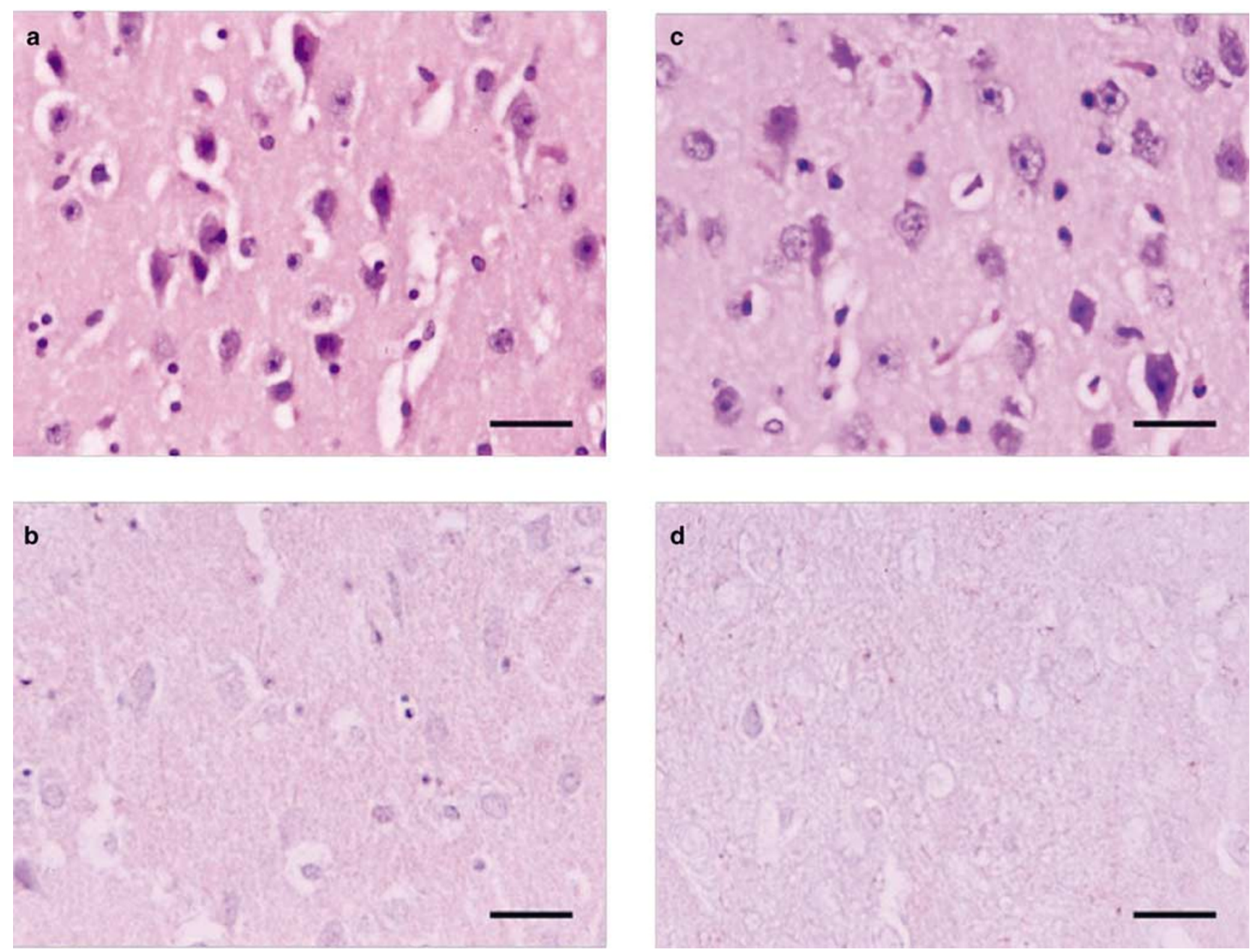

Figure 4 Histological analysis of hamster brain inoculated with $\mathrm{CM}$ muscle homogenate. Sections of the brain inoculated with PrP $\mathrm{P}_{-}$ containing muscle homogenate $(\mathbf{a}, \mathbf{b})$ or $\operatorname{PrP}^{\mathrm{CQ}}$-containing muscle homogenate $(\mathbf{c}, \mathbf{d})$ were stained with $\mathrm{HE}(\mathbf{a}, \mathbf{c})$ or immunostained using 3 F4 monoclonal antibody (b, d). Neither neurodegenerative change nor abnormal PrP deposition was revealed. Scale bars $=30 \mu \mathrm{m}$.

$1.5 \%$ NP-40. These biochemical properties of PrPCQ molecules are distinct from $\operatorname{PrP}^{\mathrm{C}}$.

There have been several attempts to create de novo $\mathrm{PrP}^{\mathrm{Sc}}$-like molecules in vitro. Using a cell-free conversion system, Horiuchi et $a l^{13}$ were able to convert $\mathrm{PrP}^{\mathrm{C}}$ into a protease-resistant isoform by the addition of $\mathrm{PrP}^{\mathrm{Sc}}$ under physiological conditions. Even in the absence of $\mathrm{PrP}^{\mathrm{Sc}}$, an acidic buffer can give a $\beta$-sheet-dominant conformation and $\mathrm{PK}$ resistance to $\mathrm{PrP}^{\mathrm{C}}$ in vitro. ${ }^{14,15}$ Nevertheless, no de novo $\mathrm{PrP}^{\mathrm{Sc}}$-like molecules succeeded to reproduce the disease in vivo. ${ }^{16}$ In the present study, $\operatorname{PrP}{ }^{\mathrm{CQ}}$ molecules were not capable of causing any pathological changes in the central nervous system. $\mathrm{PrP}^{\mathrm{CQ}}$ molecules seem to be distinct from both of these de novo $\mathrm{PrP}^{\mathrm{Sc}}$-like molecules and $\mathrm{PrP}^{\mathrm{Sc}}$, because PrP $\mathrm{PQ}^{\mathrm{CQ}}$ molecules possess neither marked resistance to PK and detergent insolubility nor transmissibility of the disease conditions.

The CM model reported in this study is different from other PrP-conversion models previously reported, in that $\mathrm{PrP} \mathrm{P}^{\mathrm{CQ}}$ molecule was generated in vivo in the absence of exogenous input of $\mathrm{PrP}^{\mathrm{Sc}}$ or $\mathrm{PrP}^{\mathrm{Sc}}$-like molecules. Instead, the microenvironment in the lysosome was altered in hamsters by the injection of chloroquine to produce this distinct $\mathrm{PrP}$ molecule. Lysosomes are acidic compartments that have been reported to play an important role in the conformational conversion of PrP in prion diseases. ${ }^{17,18}$ Chloroquine raises intralysosomal $\mathrm{pH}$ to as high as 6.0-6.5, causing marked changes in intracellular protein processing and trafficking. ${ }^{8}$ As a consequence of the long-term administration of chloroquine, skeletal muscle fibers degenerate, with numerous autophagic vacuoles. ${ }^{9}$ In the process of forming autophagic vacuoles, endogenous muscular $\mathrm{PrP}^{\mathrm{C}}$ could acquire the properties of $\mathrm{PrP}^{\mathrm{CQ}}$.

In the present study, it remains unclear whether chloroquine modifies $\mathrm{PrP}^{\mathrm{C}}$ molecules directly or indirectly. A previous study revealed that chloroquine does not directly interact with PrP molecules in scrapie-infected neuroblastoma cells. ${ }^{19}$ 
Furthermore, it has been reported that unfolded recombinant human prion protein PrP90-231 forms a stable protein folding intermediate rich in $\beta$-sheet at $\mathrm{pH}$ lower than $4 .{ }^{14}$ Matsunaga et $a l^{20}$ reported that $\mathrm{pH}$ is a crucial factor in determining the conformational state of some amyloidgenic proteins. They found that synthetic A $\beta 42$ and stefin $B$ peptides, showing similar amino-acid alignment to PrP90-144, tend to form amyloid fibrils at acidic $\mathrm{pH}$. Considering these observations, it is unlikely that chloroquine directly interacts with $\mathrm{PrP}^{\mathrm{C}}$ molecules. An increase in lysosomal $\mathrm{pH}$ due to chloroquine, and subsequent metabolic changes in lysosomal systems might be responsible for the biosynthesis of $\mathrm{PrP}^{\mathrm{CQ}}$ molecules.

Besides experimental CM, there are a few experimental models in which PrP molecules of skeletal muscle are rendered partially PK-resistant and detergent-insoluble. Chiesa et al ${ }^{21}$ established transgenic mice expressing PrP molecules with nineoctapeptide insertional mutation. Mutated $\operatorname{PrP}$ molecules obtained $\mathrm{PrP}^{\mathrm{Sc}}$-like properties in the brain and the periphery, producing neurodegeneration similar to an inherited prion disease in humans. In their model, the primary structure of PrP molecules was changed and the mutated $\operatorname{PrP}$ was overexpressed not only in the brain but also in the skeletal muscle and heart. This model is quite different from our CM model, in that the primary structure of $\operatorname{PrP}$ molecules was not manipulated.

The other experimental model is a transgenic mouse harboring high copy numbers of wild-type PrP transgenes, which spontaneously exhibited necrotizing myopathy, demyelinating polyneuropathy, and focal vacuolation of the central nervous system without apparent deposition of $\mathrm{PrP}^{\mathrm{Sc}} .{ }^{22} \mathrm{In}$ spite of severe neurodegeneration and neuromyopathy, only small amount of PK-resistant PrP was detected in affected muscles and brains. They concluded that low level of PK-resistant PrP might reflect aggregation of $\mathrm{PrP}^{\mathrm{C}}$ and was not correlated with neuropathological changes in these transgenic mice. In our study, $\mathrm{PrP}^{\mathrm{CQ}}$ after PK digestion did not show molecular characteristics of $\mathrm{PrP}^{\mathrm{Sc}}$ in prion diseases, suggesting that $\mathrm{PrP}^{\mathrm{CQ}}$ acquires less $\mathrm{PK}$ sensitivity through a different mechanism from that of $\mathrm{PrP}^{\mathrm{Sc}}$. Although the expression level of $\mathrm{PrP}$ was not increased in CM (data not shown), it is possible that distinct biochemical properties of $\mathrm{PrP}^{\mathrm{CQ}}$ might simply be due to protein aggregation or alteration in PK-protein ratio, not to the conformational change of monomeric $\mathrm{PrP}^{\mathrm{C}}$ molecules.

$\mathrm{PrP}^{\mathrm{CQ}}$ in the affected muscles of the present model was accompanied by the accumulation not only of lysosomal markers but also of those molecules known to be involved in prion disease pathogenesis, such as clathrin, heparan sulfate proteoglycan, and apolipoprotein J.23-25 It is known that certain sulfated glycans, such as heparan sulfate and pentosan polysulfate, stimulate $\mathrm{PrP}$ conversion in vitro. ${ }^{26}$ Then, it might be possible that accumulated heparan sulfate in the CM muscles contribute to the acquisition of altered PK sensitivity and partial detergent insolubility of the PrP molecules.

Experimental CM in the rat has been established previously as a model of myopathies with rimmed vacuoles, including distal myopathy with rimmed vacuole formation and inclusion-body myositis. Owing to of the deposition of amyloid $\beta$ in inclusion-body myositis, ${ }^{27}$ experimental CM has been utilized by several groups as a peripheral model to investigate the pathogenesis of Alzheimer's disease. ${ }^{10,28}$ The precise mechanism of rimmed vacuole formation in CM is still unknown; however, it has been reported that chloroquine causes an increase in endogenous autophagosomes in mammalian cells. ${ }^{29}$ Similar mechanism(s) might be shared between amyloid $\beta$ deposition in the CM rat model and $\mathrm{PrP}^{\mathrm{CQ}}$ accumulation in our $\mathrm{CM}$ hamster model.

The PrP2B polyclonal antibody revealed prominent $27 \mathrm{kDa}$ signals with additional $30 \mathrm{kDa}$ signals (Figure 2), while the $3 F 4$ monoclonal antibody reacted with dominant $35 \mathrm{kDa}$ signals and additional $30 \mathrm{kDa}$ signals (Figure 3), which were similar to Cp33-37 signal in skeletal muscle of hamster. ${ }^{30}$ The common signals of $30 \mathrm{kDa}$ were detected by both of the two antibodies. Minor epitope differences between the two antibodies might account for such a diversity of PrP signals, but it remains to be elucidated.

Finally, together with the biochemical and biological properties of $\mathrm{PrP}^{\mathrm{CQ}}$, the immunohistochemical findings in CM muscles of the molecules known to be involved in prion disease pathogenesis indicate that experimental CM in hamsters is a useful in vivo model to investigate the mechanism of PrP accumulation in the pathogenesis of PrP-related diseases.

\section{Acknowledgements}

We are grateful to Professor Mitsuo Takahashi at Fukuoka University and Professor Masami Niwa at Nagasaki University for their critique and suggestions on the research and this report. The English used in this manuscript was revised by Universal Academy Press, Inc., Japan.

This work was supported by a grant (H13-kokoro025) to KD from the Ministry of Health, Labor and Welfare of Japan.

\section{References}

1 Prusiner SB. Molecular biology of prion diseases. Science 1991;252:1515-1522.

2 Hill AF, Zeidler M, Ironside J, et al. Diagnosis of new variant Creutzfeldt-Jakob disease by tonsil biopsy. Lancet 1997;349:99-100.

3 Glazel M, Abela E, Maisson M, et al. Extraneural pathologic prion protein in sporadic Creutzfeldt-Jakob disease. N Eng J Med 2003;349:1812-1820. 
4 Bosque PJ, Ryou C, Telling G, et al. Prions in skeletal muscle. Proc Natl Acad Sci USA 2002;99:3812-3817.

5 Frederikse PH, Zigler Jr SJ, Farnsworth PN, et al. Prion protein expression in mammalian lenses. Curr Eye Res 2000;20:137-143.

6 Askanas V, Bilak M, Engel WK, et al. Prion protein is abnormally accumulated in inclusion-body myositis. Neuroreport 1993;5:25-28.

7 Zanusso G, Vattemi G, Ferrari S, et al. Increased expression of the normal cellular isoform of prion protein in inclusion-body myositis, inflammatory myopathies and denervation atrophy. Brain Pathol 2001;11:182-189.

8 Holzman E. Lysosomes. Cellular organelles. Plenum Press: New York and London, 1989.

9 Macdonald RD, Engel AG. Experimental chloroquine myopathy. J Neuropath Exp Neurol 1970;29:479-499.

10 Tsuzuki K, Fukatsu R, Takamaru Y, et al. Co-localization of amyloid-associated proteins with amyloid beta in rat soleus muscle in chloroquine-induced myopathy: a possible model for amyloid beta formation in Alzheimer's disease. Brain Res 1995;699:260-265.

11 Kitamoto T, Shin RW, Doh-ura K, et al. Abnormal isoform of prion protein accumulates in the synaptic structures of the central nervous system in patients with Creutzfeldt-Jakob disease. Am J Path 1992;140: 1285-1294.

12 Lehmann S, Harris DA. Blockade of glycosylation promotes acquisition of scrapie-like properties by the prion protein in cultured cells. J Biol Chem 1997; 272:21479-21487.

13 Horiuchi M, Caughey B. Specific binding of normal prion protein to the scrapie form via a localized domain initiates its conversion to the protease-resistant state. EMBO J 1999;18:3193-3203.

14 Swietnicki W, Peterson R, Gambetti $\mathrm{P}$, et al. $\mathrm{pH}-$ dependent stability and conformation of the recombinant human prion protein $\operatorname{PrP}(90-231)$. J Biol Chem 1997;272:27517-27520.

15 Matsunaga Y, Peretz D, Williamson A, et al. Cryptic epitope in N-teminally truncated prion protein are exposed in the full-length molecule: dependence of conformation on pH. Proteins 2001;44:110-118.

16 Hill AF, Antoniou M, Collinge J. Protease-resistant prion protein produced in vitro lacks detectable infectivity. J Gen Virol 1999;80:11-14.

17 Laszlo L, Lowe J, Self T, et al. Lysosomes as key organelles in the pathogenesis of prion encephalopathies. J Pathol 1992;166:333-341.

18 Shyng SL, Huber MT, Harris DA. A prion protein cycles between the cell surface and an endocytic compartment in cultured neuroblastoma cells. J Biol Chem 1993;268:15922-15928.

19 Doh-ura K, Iwaki T, Caughey B. Lysosomotropic agents and cysteine protease inhibitors inhibit scrapieassociated prion protein accumulation. J Virol 2000;74:4894-4897.

20 Matsunaga Y, Zerovnik E, Yamada T, et al. Conformational changes preceding amyloid-fibril formation of amyloid-beta and stefin B: parallels in $\mathrm{pH}$ dependence. Curr Med Chem 2002;9:1717-1724.

21 Chiesa R, Pestronk A, Schmidt RE, et al. Primary myopathy and accumulation of PrPSc-like molecules in peripheral tissues of transgenic mice expressing a prion protein insertional mutation. Neurobiol Dis 2001;8:279-288.

22 Westaway D, DeArmond SJ, Cayetano-Canlas J, et al. Degeneration of skeletal muscle, peripheral nerves, and the central nervous system in transgenic mice overexpressing wild-type prion proteins. Cell 1994, 76:117-129.

23 Mouillet-Richard S, Ermonval M, Chebassier C, et al. Signal transduction through prion protein. Science 2000;289:1925-1928.

24 McBride PA, Wilson MI, Eikeleboom P, et al. Heparan sulfate proteoglycan is associated with amyloid plaques and neuroanatomically targeted PrP pathology throughout the incubation period of scrapie-infected mice. Exp Neurol 1998;149:447-454.

25 Sasaki K, Doh-ura K, Ironside JW, et al. Increased clusterin (apolipoprotein J) expression in human and mouse brains infected with transmissible spongiform encephalopathies. Acta Neuropathol (Berl) 2002;103 199-208.

26 Wong C, Xiong LW, Horiuchi M, et al. Sulfated glycans and elevated temperature stimulate $\mathrm{PrP}^{\mathrm{Sc}}$-dependent cell-free formation of protease-resistant prion protein. EMBO J 2001;20:377-386.

27 Askanas V, Engel WK, Alvarez RB, et al. Betaamyloid protein immunoreactivity in muscle of patients with inclusion-body myositis. Lancet 1992; 339:560-561.

28 Murakami N, Oyama F, Gu Y, et al. Accumulation of tau in autophagic vacuoles in chloroquine myopathy. J Neuropathol Exp Neurol 1998;57:664-673.

29 Suzuki T, Nakagawa M, Yoshikawa A, et al. The first molecular evidence that autophagy relates rimmed vacuole formation in chloroquine myopathy. J Biochem 2002;131:647-651.

30 Bendheim PE, Brown HR, Rudelli RD, et al. Nearly ubiquitous tissue distribution of the scrapie agent precursor protein. Neurology 1992;42:149-156. 